\title{
RESPONSE OF LABILE ORGANIC MATTER FRACTIONS TO PLASTIC FILM REMOVAL DURING MAIZE (ZEA MAYS L.) GROWTH IN SEMIARID FARMLAND SOIL
}

\author{
WANG, S. J. ${ }^{1}-$ LUO, S. S. $.^{*}-$ LI, S. Q..$^{3^{*}}$ \\ ${ }^{I}$ College of Resource and Environment, Key Laboratory of Soil Resource Sustainable \\ Utilization for Jilin Province Commodity Grain Bases, Jilin Agricultural University, \\ Changchun 130118, China \\ ${ }^{2}$ Key Laboratory of Mollisols Agroecology, Northeast Institute of Geography and Agroecology, \\ Chinese Academy of Sciences, Changchun 130102, China \\ ${ }^{3}$ State Key Laboratory of Soil Erosion and Dryland Farming on the Loess Plateau, Chinese \\ Academy of Sciences and Ministry of Water Resource, Yangling 712100, China \\ *Corresponding authors \\ e-mail:shasha0705@hotmail.com; sqli@ms.iswc.ac.cn \\ (Received $17^{\text {th }}$ Apr 2019; accepted $15^{\text {th }}$ Nov 2019)
}

\begin{abstract}
Understanding the differences of labile soil organic matter between plastic film mulching at all growing stages (FM) and plastic film removal after the silking stage (RM) is essential to identify changes in soil quality and $\mathrm{N}$ availability. Compared to the FM treatment, the RM treatment significantly decreased the microbial biomass $\mathrm{C}(\mathrm{MBC})$ content, water soluble organic $\mathrm{C}$ content in the $0-20 \mathrm{~cm}$ layer and extractable organic C content in 2011 at milk stage (R3); however, it significantly increased the MBC content at planting time (PT) or the 6th leaf stage (V6) of the next growing season. Moreover, compared with the FM treatment, the RM treatment significantly increased the microbial biomass $\mathrm{N}$ content from silking stage to physiological maturity (R6) in the $0-20 \mathrm{~cm}$ layer and extractable organic N (EON) content at R6 in 2012; however, it significantly decreased the water soluble organic N (WSON) content at R3 and the WSON and EON contents at PT or V6 of the next growing season. Thus, plastic film mulching with film removal during the maize reproductive stages could be an excellent option for maintaining soil quality and improving soil $\mathrm{N}$ availability in the temperature- and rainfall-limited regions of northwest China.
\end{abstract}

Keywords: plastic film mulching, microbial biomass carbon, microbial biomass nitrogen, dissolved organic carbon, dissolved organic nitrogen

\section{Introduction}

Plastic film mulching is a worldwide agricultural technology with direct economic and environmental benefits, such as improving crop productivity, increasing water-use efficiency, improving soil quality, reducing greenhouse gas emissions, and reducing nitrate leaching (Wang et al., 2017; Liu et al., 2014b, 2015, 2016). The Loess Plateau has a typical semi-arid monsoon climate, in which maize (Zea mays L.) is one of the most common grain crops; however, low temperature and drought in the early growth stage of spring crops often lead to low crop yield (Liu et al., 2009). Up to this day, plastic film mulching has been widely used on the Loess Plateau (Zhou et al., 2012; Liu et al., 2014c; Li et al., 2018), which can significantly improve crop yield by increasing soil moisture and topsoil temperature (Liu et al., 2010; 2014a; Bu et al., 2013b). The rainy season on the Loess Plateau ranges from July to September and coincides with the spring maize reproductive stages (RS) (Liu et al., 2010). During this period, plastic film mulching is detrimental to crop yield, in some conditions (e.g., high air temperatures), 
most likely because it increases soil temperature and accelerates leaf and root senescence during the spring maize RS (Liu et al., 2010, 2014a). Compared with plastic film mulching for the entire maize growing season, plastic film removal during the spring maize RS decreased the leaf and root senescence rate and increased the final crop yield (Liu et al., 2014a; Luo et al., 2016). Although there are some reports about the effects of different mulching periods during crop growing season on crop yield and soil properties (Wang et al., 2009; Luo et al., 2016), there is limited information about the effects of plastic film removal during the spring maize RS on labile soil organic matter (SOM) pools, relative to retaining them throughout the whole maize growing season. Our previous studies have shown that plastic film removal during the spring maize RS significantly increased soil organic carbon (SOC), total nitrogen (TN), extractable organic $\mathrm{C}(\mathrm{EOC}), \mathrm{KMnO}_{4}$-oxidizable $\mathrm{C}\left(\mathrm{KMnO}_{4}-\mathrm{C}\right)$ and $\mathrm{C}$ management index $(\mathrm{CMI})$ in the $0-20 \mathrm{~cm}$ layer, as well as light fraction organic $\mathrm{C}$ (LFOC), light fraction organic $\mathrm{N}$ (LFON), microbial biomass $\mathrm{C}(\mathrm{MBC}), \mathrm{EOC}$, extractable organic $\mathrm{N}(\mathrm{EON}), \mathrm{KMnO}_{4}-\mathrm{C}$ and CMI in the 20-40 cm layer after the 5-yr cultivation (Luo et al., 2016).

As labile SOM pools, soil microbial biomass and dissolved organic matter are strongly affected by soil management and therefore sensitive and important parameters of soil fertility and quality (Haynes, 2005). Soil microorganisms are responsible for transforming organic matter into inorganic nutrients (Ryan et al., 2009). Dissolved organic matter (DOM) represents a mobile source of energy and food for soil microorganisms (Kalbitz et al., 2000) and a primary source of mineralizable N, P and S, thus making a significant contribution to nutrient availability and cycling (Haynes, 2005). Accordingly, measuring labile SOM fractions such as MBC, microbial biomass $\mathrm{N}(\mathrm{MBN})$, water soluble organic $\mathrm{C}$ (WSOC), water soluble organic $\mathrm{N}$ (WSON), EOC and EON are essential to identifying changes in soil quality and fertility. A few studies have investigated the effects of fertilization and plastic film mulching on the changes of soil microbial biomass during maize growth (Liang et al., 2011; Liu et al., 2014c). Until now, little has been known about the effects of plastic film removal during the spring maize RS on the changes of soil microbial biomass and other labile SOM fractions in semiarid farmland. This study was designed to: (1) reveal the impacts of plastic film removal during the spring maize RS on the labile SOM pools during the whole maize growth; and (2) evaluate the effects on soil fertility and environmental sustainability. We hypothesized that the changes in labile organic $\mathrm{C}$ and $\mathrm{N}$ pools with the plant growth vary largely between retaining and removing plastic film during the spring maize RS, thereby generate the cumulative effect of early season residue inputs for the next growing season. This information will be useful for understanding the SOM dynamics and developing the integrated management practices to improve SOM quantity and quality in a spring maize cropping system on the semiarid Loess Plateau.

\section{Materials and methods}

\section{Site description}

The study was conducted in 2011 and 2012 at Changwu Agricultural and Ecological Experimental Station $\left(35.28^{\circ} \mathrm{N}, 107.88^{\circ} \mathrm{E}, 1200 \mathrm{~m}\right.$ altitude), which is located in semiarid area on the Loess Plateau of China (Fig. 1). The environmental information and soil properties of study site were described in Luo et al. (2016). The annual mean air temperature is $9.7^{\circ} \mathrm{C}$, and the average annual precipitation from 1957 to 2010 is $582 \mathrm{~mm}$ with $73 \%$ of this falls during the maize growth season. The soil at the study site 
is developed from loess and had a silt loam texture according to the USDA texture classification system. The soil properties at the top $20 \mathrm{~cm}$ were: bulk density $1.3 \mathrm{~g} \mathrm{~cm}^{-3}$, pH 8.4, SOC $8.2 \mathrm{~g} \mathrm{~kg}^{-1}$, TN $1.05 \mathrm{~g} \mathrm{~kg}^{-1}$, mineral $\mathrm{N} 28.8 \mathrm{mg} \mathrm{kg}^{-1}$, available phosphorus (Olsen-P) $20.7 \mathrm{mg} \mathrm{kg}^{-1}$, and available potassium $\left(\mathrm{NH}_{4} \mathrm{OAc}-\mathrm{K}\right) 133.1 \mathrm{mg} \mathrm{kg}^{-1}$ in April 2009, prior to the start of the experiment (Luo et al., 2016).

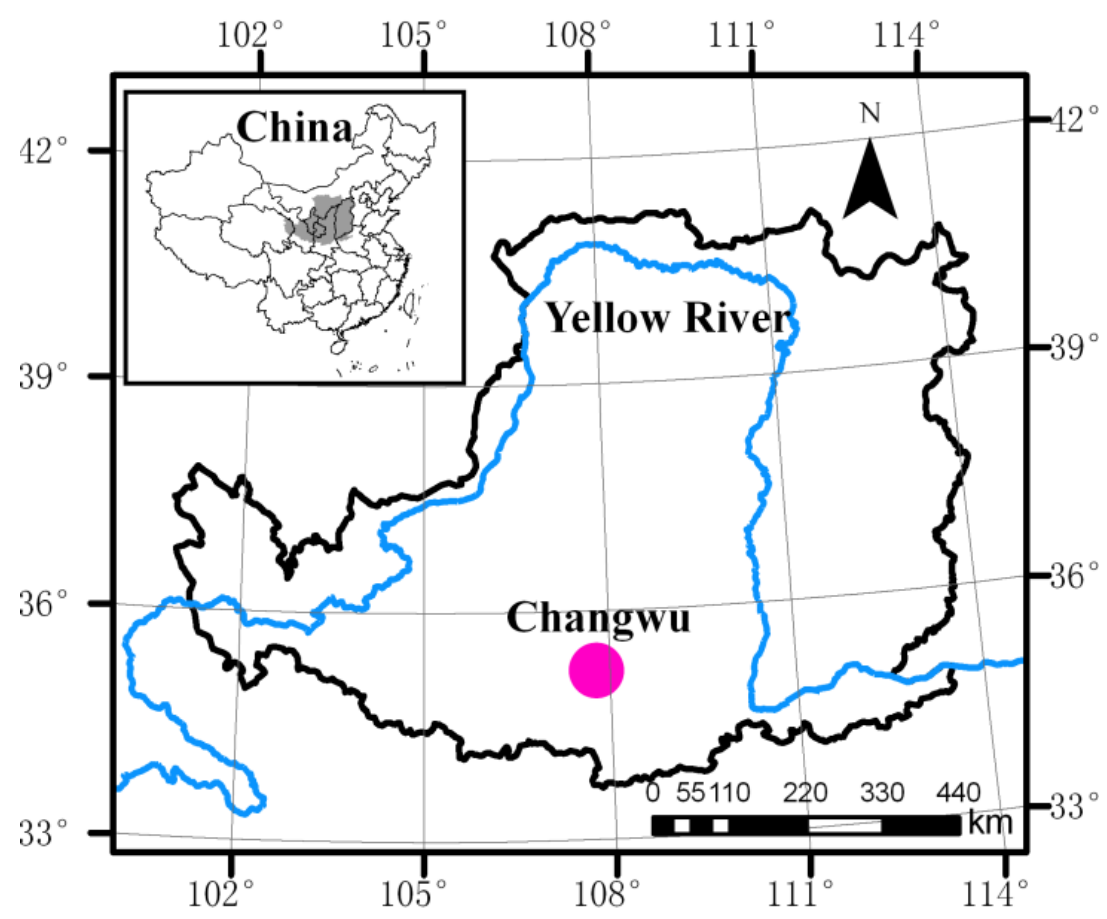

Figure 1. The location of Changwu Agricultural and Ecological Experimental Station $\left(35.28^{\circ} \mathrm{N}\right.$, $107.88^{\circ} \mathrm{E}, 1200 \mathrm{~m}$ altitude) on the Loess Plateau of China. (Luo et al., 2019)

\section{Experimental design and field management}

The detail information of experimental design and field management were described in Luo et al. (2016). We applied two treatments, including plastic film mulching during all growing stages $(\mathrm{FM})$ and plastic film removal at the silking stage (RM), to maize plots with a density of 85,000 plants $\mathrm{ha}^{-1}$. A high-yielding maize hybrid (Pioneer 335) was used in this study. The treatments were applied to $56 \mathrm{~m}^{2}(8 \mathrm{~m} \times 7 \mathrm{~m})$ plots arranged in a randomly block design with three replicates. After ridging the treatment plots, chemical fertilizers were broadcast over the soil at a rate of $90 \mathrm{~kg} \mathrm{~N} \mathrm{ha}^{-1}$ in the form of urea (containing $46 \% \mathrm{~N}), 40 \mathrm{~kg} \mathrm{P} \mathrm{ha}^{-1}$ in the form of calcium super phosphate $(12 \%$ $\left.\mathrm{P}_{2} \mathrm{O}_{5}\right), 80 \mathrm{~kg} \mathrm{~K} \mathrm{ha}^{-1}$ in the form of potassium sulfate $\left(45 \% \mathrm{~K}_{2} \mathrm{O}\right)$, and $30 \mathrm{t} \mathrm{ha}^{-1}$ organic manure was broadcast over the soil; the soil was then plowed to mixed the fertilizer into the subsurface. Plastic film $(0.005 \mathrm{~mm}$ thick, $1.2 \mathrm{~m}$ wide and transparent) was used to cover the soil. The maize was planted at $5 \mathrm{~cm}$ deep using a hole-sowing machine on 21 and 28 April in 2011 and 2012, respectively, and maize plants were harvested on 5 and 19 September in 2011 and 2012, respectively.

All of the plots were top-dressed twice with $67.5 \mathrm{~kg} \mathrm{~N} \mathrm{ha}^{-1}$ (urea, 46\% $\mathrm{N}$ ) during the 10th leaf stage (V10) and silking stage (R1) recorded according to the standardized maize development stage system (Ritchie et al., 1992), using the same handheld device as used for sowing. 


\section{Sampling and measurements}

The standardised maize development stage system was used to identify the vegetative (VS, from seedling emergence to silking) and reproductive (RS, from silking to physiological maturity) stages of the entire growing season (Ritchie et al., 1992). During the growing season, three adjacent plants were sampled at the 6th leaf stage (V6), V10, R1, milk stage (R3) and physiological maturity (R6) to measure the aboveground biomass. At maturity, the grain yield was measured for all plants selected from a $10 \mathrm{~m}^{2}$ area in each plot. The aboveground biomass and grain yield were determined based on the average of three plot replicates, and all samples were dried to a constant weight in a fan oven at $75^{\circ} \mathrm{C}$.

Soil samples were collected at planting time (PT, before fertilization and sowing), V6, V10, R1, R3 and R6. At each plot, soil cores were drilled randomly using a 4-cm diameter auger with five replications and then mixed together to form one composite sample for every soil depth $(0-20 \mathrm{~cm}$ and $20-40 \mathrm{~cm})$. Soil moisture of each sample was measured after removing visible plant residues and sands, and then soil sample passed through a 2-mm sieve. The samples were refrigerated $\left(0-4{ }^{\circ} \mathrm{C}\right)$ until $\mathrm{MBC}, \mathrm{MBN}$, WSOC, WSON, EOC and EON were determined.

MBC and MBN were measured using a modified chloroform fumigation-extraction method (Brookes et al., 1985; Vance et al., 1987). Briefly, $12.5 \mathrm{~g}$ fresh soil samples were fumigated with alcohol-free chloroform at $25^{\circ} \mathrm{C}$ for $24 \mathrm{~h}$. Excess chloroform was removed by repeated evacuation, the fumigated and non-fumigated samples promptly were extracted with $50 \mathrm{~mL} 0.5 \mathrm{~mol} \mathrm{~L}^{-1} \mathrm{~K}_{2} \mathrm{SO}_{4}$ (soil/solution ratio of $1: 4 \mathrm{w} / \mathrm{v}$ ) on a rotary shaker at $220 \mathrm{r} \mathrm{min}^{-1}$ for $0.5 \mathrm{~h}$. After shaking, the supernatant was filtered using a membrane filter, and then filtrate was immediately frozen at $-20{ }^{\circ} \mathrm{C}$. Total organic $\mathrm{C}$ concentration in the filtrate was measured using an automated total organic $\mathrm{C}$ analyzer (TOC-Vcph, Shimadzu, Japan). Total soluble $\mathrm{N}$ in the filtrate was followed by alkaline persulfate oxidation and measured by dual-wavelength ultraviolet spectrophotometry (Norman et al., 1985; Cabrera and Beare, 1993). MBC and MBN were calculated by taking the difference between total organic $\mathrm{C}$ and soluble $\mathrm{N}$ of the fumigated and nonfumigated soils, respectively. A $K_{C}$ value of 0.45 (Vance et al., 1987) and a $K_{N}$ value of 0.54 (Brookes et al., 1985) were used to calculate the $\mathrm{C}$ and $\mathrm{N}$ content of the microbial biomass.

WSOC and WSON were extracted from $20 \mathrm{~g}$ fresh soil with $40 \mathrm{~mL}$ deionized water (soil/solution ratio of $1: 2 \mathrm{w} / \mathrm{v}$ ) at $25^{\circ} \mathrm{C}$. After shaking at $250 \mathrm{r} \mathrm{min}^{-1}$ for $0.5 \mathrm{~h}$, and then centrifuging for $10 \mathrm{~min}$ at $8000 \mathrm{r} \mathrm{min}^{-1}$, the supernatant was filtered using a $0.45-\mu \mathrm{m}$ membrane filter, and then filtrate was immediately frozen at $-20^{\circ} \mathrm{C}$ (Liang et al., 1998). EOC and EON were extracted from $10 \mathrm{~g}$ of fresh soil with $50 \mathrm{~mL} 0.5 \mathrm{~mol} \mathrm{~L}^{-1} \mathrm{~K}_{2} \mathrm{SO}_{4}$ (soil/solution ratio of $1: 5 \mathrm{w} / \mathrm{v}$ ) at $25{ }^{\circ} \mathrm{C}$. After shaking for $1 \mathrm{~h}$ at a speed of $220 \mathrm{r} \mathrm{min}^{-1}$, the supernatant was filtered using a $0.45-\mu \mathrm{m}$ membrane filter, and then filtrate was immediately frozen at $-20{ }^{\circ} \mathrm{C}$ (Jones and Willett, 2006). Total organic $\mathrm{C}$ concentration in the filtrate was measured using an automated total organic $\mathrm{C}$ analyzer (TOC-Vcph, Shimadzu, Japan). The filtrate was later defrosted at room temperature and analyzed for mineralization $\mathrm{N}\left(\mathrm{NH}_{4}{ }^{+}-\mathrm{N}\right.$ and $\left.\mathrm{NO}_{3}^{-}-\mathrm{N}\right)$ with a continuous flow analyzer (FLOWSYS, Italy), and total soluble $\mathrm{N}$ by dual-wavelength ultraviolet spectrophotometry after alkaline persulfate oxidation (Cabrera and Beare, 1993; Norman et al., 1985). Total organic $\mathrm{N}$ concentration in the filtrate was calculated by taking the difference between total soluble $\mathrm{N}$ and mineralization $\mathrm{N}$. 


\section{Statistical analysis}

The effects of plastic film removal on the measured parameters were evaluated using Independent-Samples T-Test. In all cases, differences were deemed to be significant if $\mathrm{p}<0.05$ using SPSS version 20.0.

\section{Results}

\section{Air temperature and precipitation}

The monthly precipitation and mean air temperature at the study site during the two experimental years were measured at the Changwu meteorological monitoring station, which is situated within $50 \mathrm{~m}$ of the experimental site (Fig. 2). One wet year occurred in 2011 and one dry year occurred in 2012 compared with the average for the preceding $54 \mathrm{yr}$ (1957-2010). In this study site, the annual mean air temperatures were both $9.4^{\circ} \mathrm{C}$ in two years, and the precipitation was $644 \mathrm{~mm}$ in 2011 and $481 \mathrm{~mm}$ in 2012. During the maize growth season (May to September), the mean air temperature was $18.2^{\circ} \mathrm{C}$ in 2011 and $18.7{ }^{\circ} \mathrm{C}$ in 2012 , which is lower than the 54-yr mean $\left(19.0{ }^{\circ} \mathrm{C}\right)$, and the precipitation was $14 \%$ greater than the 54-yr mean $(426 \mathrm{~mm})$ in 2011 and $15 \%$ less than the 54-yr mean in 2012. The precipitation during the rainy season (July to September) was $25 \%$ greater than the $54-y r$ mean $(310 \mathrm{~mm})$ in 2011 and close to the $54-y r$ mean in 2012. Compared with the 54-yr mean, the precipitation was greater in spring maize reproductive stages of 2011, and lower in spring maize vegetative stages of 2012. The mean air temperature during the rainy season was $18.4^{\circ} \mathrm{C}$ in 2011 and $19.1^{\circ} \mathrm{C}$ in 2012 , which is lower than the $54-\mathrm{yr}$ mean $\left(19.8^{\circ} \mathrm{C}\right)$.

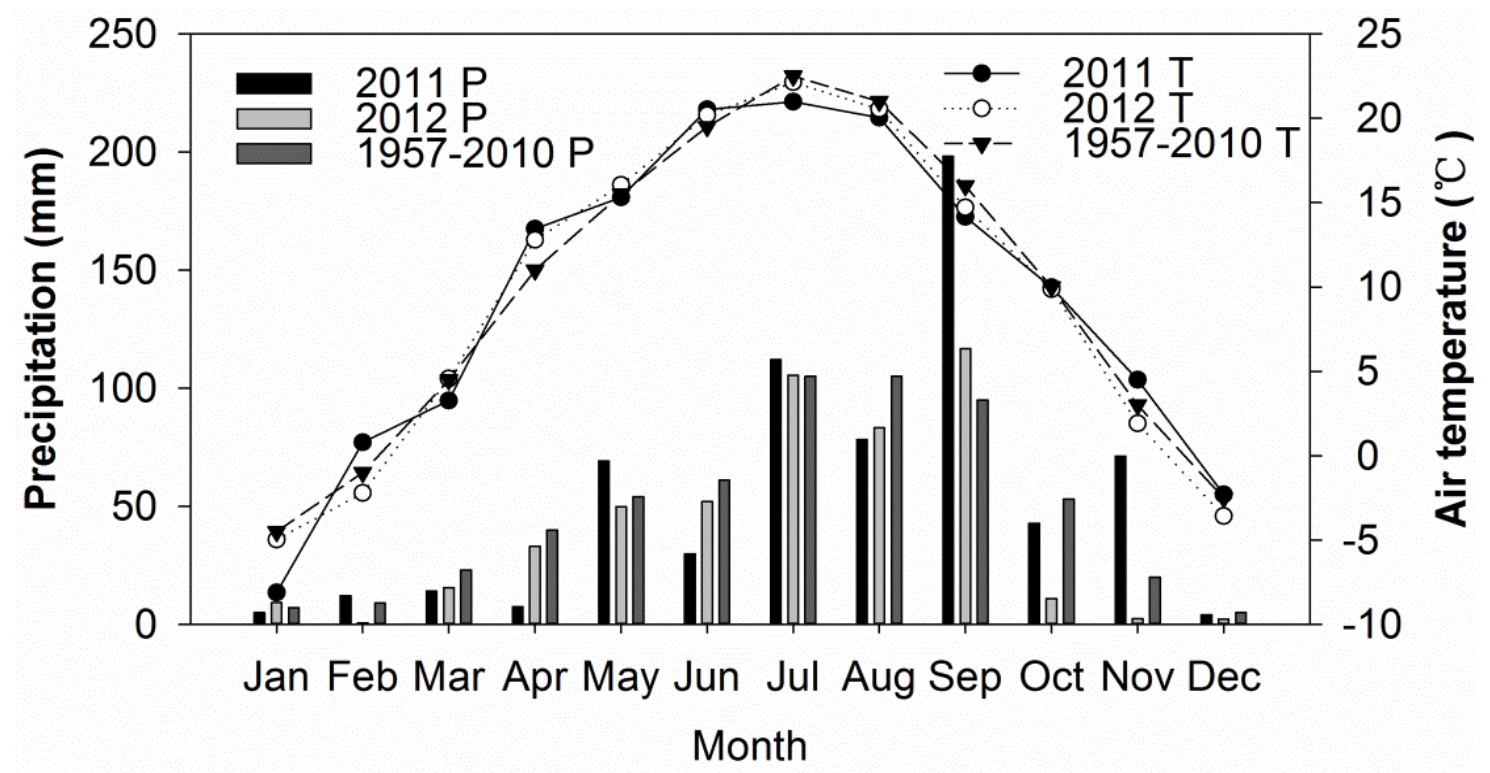

Figure 2. The monthly precipitation $(P)$ and mean air temperature $(T)$ at the study site

\section{Total aboveground biomass and grain yield}

Compared with the FM treatment, the RM treatment significantly increased the total aboveground biomass at V6 and V10 in 2011 and at V10 in 2012 (Table 1). However, 
there was no significant difference in the total aboveground biomass between the two treatments from R1 to R6 (Table 1). Table 1 shows that plastic film removal had no significant effect on the aboveground biomass during the RS (from R1 to R6) of the current growing season, but it may promote the aboveground biomass during the VS (V6 or V10) of the next growing season. Compared with the FM treatment, the RM treatments lightly increased the grain yield by $8.7 \%$ in 2011 and $4.1 \%$ in 2012, while the differences were not significant (Table 1).

Table 1. Effects of plastic film mulching (FM) and removal (RM) on the total aboveground biomass and grain yield in 2011 and 2012

\begin{tabular}{|c|c|c|c|c|c|}
\hline \multirow{2}{*}{\multicolumn{2}{|c|}{ Sampling time }} & \multicolumn{2}{|c|}{ Total aboveground biomass (t ha $\left.{ }^{-1}\right)$} & \multicolumn{2}{|c|}{ Grain yield (t ha' $\left.{ }^{-1}\right)$} \\
\hline & & \multirow{2}{*}{$\frac{\text { FM }}{0.58 b}$} & \multirow{2}{*}{$\frac{\mathbf{R M}}{0.71 \mathrm{a}}$} & \multirow[t]{2}{*}{ FM } & \multirow[t]{2}{*}{$\mathbf{R M}$} \\
\hline \multirow{5}{*}{2011} & V6 & & & & \\
\hline & V10 & $4.92 b$ & $5.71 \mathrm{a}$ & & \\
\hline & $\mathrm{R} 1$ & $12.76 \mathrm{a}$ & $11.78 \mathrm{a}$ & & \\
\hline & R3 & $19.69 \mathrm{a}$ & $19.67 \mathrm{a}$ & & \\
\hline & R6 & $23.56 \mathrm{a}$ & $24.43 \mathrm{a}$ & $14.42 \mathrm{a}$ & $15.67 \mathrm{a}$ \\
\hline \multirow{5}{*}{2012} & V6 & $0.75 \mathrm{a}$ & $0.76 \mathrm{a}$ & & \\
\hline & V10 & $5.25 \mathrm{~b}$ & $5.83 \mathrm{a}$ & & \\
\hline & R1 & $11.63 \mathrm{a}$ & $11.79 \mathrm{a}$ & & \\
\hline & R3 & $17.10 \mathrm{a}$ & $16.85 \mathrm{a}$ & & \\
\hline & R6 & $23.65 \mathrm{a}$ & $24.17 \mathrm{a}$ & $14.57 \mathrm{a}$ & $15.17 \mathrm{a}$ \\
\hline
\end{tabular}

Means $(n=3)$ followed by different lowercase letters within a row are significantly $(\mathrm{p}<0.05)$ different between mulching practices. V6, V10, R1, R3, R6 denote the 6th leaf stage, the 10th leaf stage, silking stage, milk stage and physiological maturity, respectively

\section{Microbial biomass $C$ and $N$}

Microbial biomass $\mathrm{C}$ content ranged from 175.9 to $454.0 \mathrm{mg} \mathrm{kg}^{-1}$ in the $0-20 \mathrm{~cm}$ layer (Fig. 3a, b), compared to a range of 107.9 to $227.8 \mathrm{mg} \mathrm{kg}^{-1}$ in the $20-40 \mathrm{~cm}$ layer (Fig. 3c,d). The MBC content was higher in the $0-20 \mathrm{~cm}$ layer than that in the $20-40 \mathrm{~cm}$ layer $(p<0.001)$. Meanwhile, the MBC content was higher during the wet year (2011) than that during the dry year (2012) at sampling times from V6 to R1 $(p<0.001)$. For most of sampling times, the two layers had a similar trend in the MBC content. Compared with the FM treatment, the MBC content under RM significantly increased at V6 in 2011 and at PT in 2012 in the 0-20 cm layer (Fig. 3a, b), as well as at PT in 2011 and 2012 in the 20-40 cm layer (Fig. 3c,d); the MBC content under RM significantly decreased at R3 in 2011 and 2012 in the 0-20 cm layer (Fig. 3a, b). Figure 2 shows that plastic film removal had a significant negative effect on the MBC content at R1 of the current growing season in the $0-20 \mathrm{~cm}$ layer, but it may promote the $\mathrm{MBC}$ content at PT or V6 of the next growing season in the two layers.

Microbial biomass $\mathrm{N}$ content ranged from 17.5 to $76.9 \mathrm{mg} \mathrm{kg}^{-1}$ in the $0-20 \mathrm{~cm}$ layer (Fig. 3e, f), compared to a range of 14.2 to $37.3 \mathrm{mg} \mathrm{kg}^{-1}$ in the $20-40 \mathrm{~cm}$ layer (Fig. $3 g$, h). The MBN content was higher in the $0-20 \mathrm{~cm}$ layer than that in the $20-40 \mathrm{~cm}$ layer 
$(p<0.001)$. The MBN content was lower during the wet year (2011) than that during the dry year (2012) at sampling times from V10 to R6 $(p<0.001)$. For most of sampling times, the two layers had a similar trend in the MBN content.

\section{Water soluble organic $C$ and $N$}

Water soluble organic $\mathrm{C}$ content ranged from 51.2 to $122.7 \mathrm{mg} \mathrm{kg}^{-1}$ in the $0-20 \mathrm{~cm}$ layer (Fig. $4 a, b$ ), compared to a range of 29.3 to $76.5 \mathrm{mg} \mathrm{kg}^{-1}$ in the $20-40 \mathrm{~cm}$ layer (Fig. 4c, d). The WSOC content was higher in the $0-20 \mathrm{~cm}$ layer than that in the 20 $40 \mathrm{~cm}$ layer $(p<0.001)$. For most of sampling times, the two layers had a similar change trend in the WSOC content. In 2011, compared with the FM treatment, the RM treatment generally decreased the WSOC content in the $0-20 \mathrm{~cm}$ layer, whereas increased that in the 20-40 cm layer (Fig. 4a, c). Compared with the FM treatment, the RM treatment significantly decreased the WSOC content in the $0-20 \mathrm{~cm}$ layer at PT in 2011 and at R3 and R6 in 2012 (Fig. 4a, b), whereas significantly increased that in the 20-40 cm layer from R1 to R6 in 2011 and from V10 to R3 in 2012 (Fig. 4c, d). Figure 3 shows that plastic film removal had a significant active effect on the WSOC content in the 20-40 cm layer during the rainy season (from R1 to R3) in two years.

Water soluble organic $\mathrm{N}$ content ranged from 2.6 to $20.0 \mathrm{mg} \mathrm{kg}^{-1}$ in the $0-20 \mathrm{~cm}$ layer (Fig. $4 e, f$ ), compared to a range of 1.5 to $15.5 \mathrm{mg} \mathrm{kg}^{-1}$ in the $20-40 \mathrm{~cm}$ layer (Fig. $4 g, h$ ). For most of sampling times, the two layers had a similar change trend in the WSON content. Compared with the FM treatment, the RM treatment significantly decreased the WSON content in the $0-20$ and $20-40 \mathrm{~cm}$ layers at R3 in two years (Fig. 4e-h); meanwhile, the RM treatment significantly decreased the WSON content in the 20-40 cm layer at PT in two years and at V6 and R6 in 2012 (Fig. 4g, h). Figure 3 shows that plastic film removal had a significantly negative effect on the WSON content in the whole $0-40 \mathrm{~cm}$ layer at R3 and this negative effect may persist into the early stage of the next growing season in the $20-40 \mathrm{~cm}$ layer.

\section{Extractable organic $C$ and $N$}

Extractable organic $\mathrm{C}$ content ranged from 58.7 to $144.3 \mathrm{mg} \mathrm{kg}^{-1}$ in the $0-20 \mathrm{~cm}$ layer (Fig. $5 a, b$ ), compared to a range of 27.9 to $68.1 \mathrm{mg} \mathrm{kg}^{-1}$ in the $20-40 \mathrm{~cm}$ layer (Fig. $5 c, d$ ). The EOC content was higher in the $0-20 \mathrm{~cm}$ layer than that in the $20-40 \mathrm{~cm}$ layer $(p<0.001)$. For most of sampling times, the two layers had a similar change trend in the EOC content. Compared with the FM treatment, the RM treatment significantly decreased the EOC content in the 0-20 and 20-40 cm layers at R3 in 2011 (Fig. 5a, c); meanwhile, the RM treatment significantly decreased the EOC content at R3 in the 0$20 \mathrm{~cm}$ layer in 2012 (Fig. 5b). Fig. 4 shows that plastic film removal had a significantly negative effect on the EOC content in the $0-20 \mathrm{~cm}$ layer at R3 in two years and this negative effect may extend into the $20-40 \mathrm{~cm}$ layer at R3 in the wet year (2011).

Extractable organic $\mathrm{N}$ content ranged from 8.2 to $26.0 \mathrm{mg} \mathrm{kg}^{-1}$ in the $0-20 \mathrm{~cm}$ layer (Fig. $5 e, f$ ), compared to a range of 5.6 to $16.2 \mathrm{mg} \mathrm{kg}^{-1}$ in the $20-40 \mathrm{~cm}$ layer (Fig. $5 g$, $h)$. The EON content was higher in the $0-20 \mathrm{~cm}$ layer than that in the $20-40 \mathrm{~cm}$ layer $(p<0.001)$. For most of sampling times, the two layers had a similar change trend in the EON content. Compared with the FM treatment, the RM treatment significantly decreased the EON content in the 0-20 cm layer from PT to V10 in 2012 (Fig. 5f) and in the 20-40 cm layer at PT in two years (Fig. $5 g, h$ ), but the RM treatment significantly increased the EON content in the 0-20 and 20-40 cm layers at R6 in 2012 (Fig. 5f, h). 


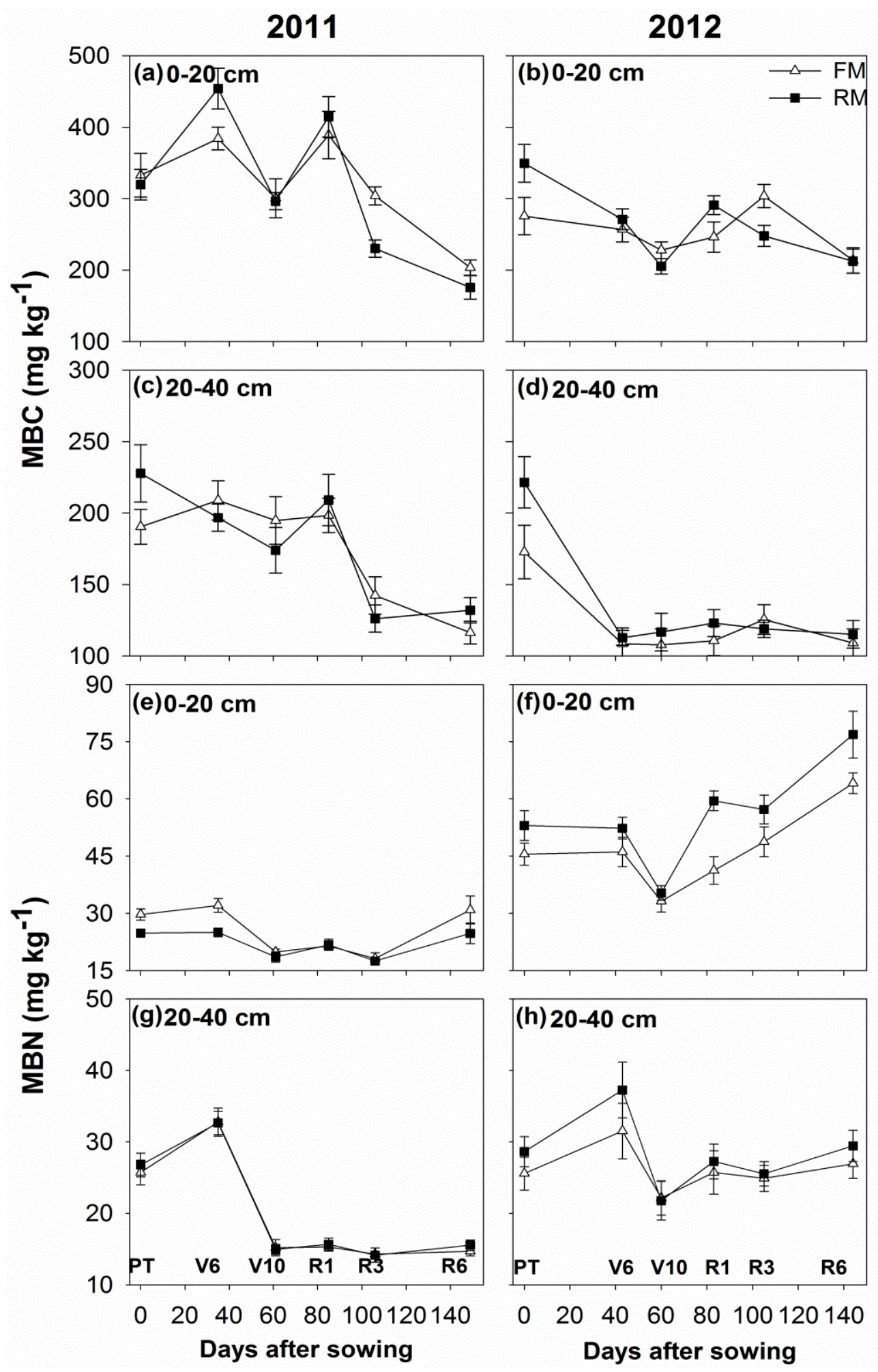

Figure 3. Microbial biomass $C$ and $N$ under different mulching practices in the 0-20 and 20-40 $\mathrm{cm}$ layers during the maize growing season in 2011 and 2012. Error bars represent standard errors of the means $(n=3)$. FM denote the treatment with plastic film mulching during all growing stages, RM denote the treatment with plastic film removal at the silking stage. PT, V6, $V 10, R 1, R 3, R 6$ denote the planting time before fertilization and sowing, the 6th leaf stage, the 10th leaf stage, silking stage, milk stage and physiological maturity, respectively 

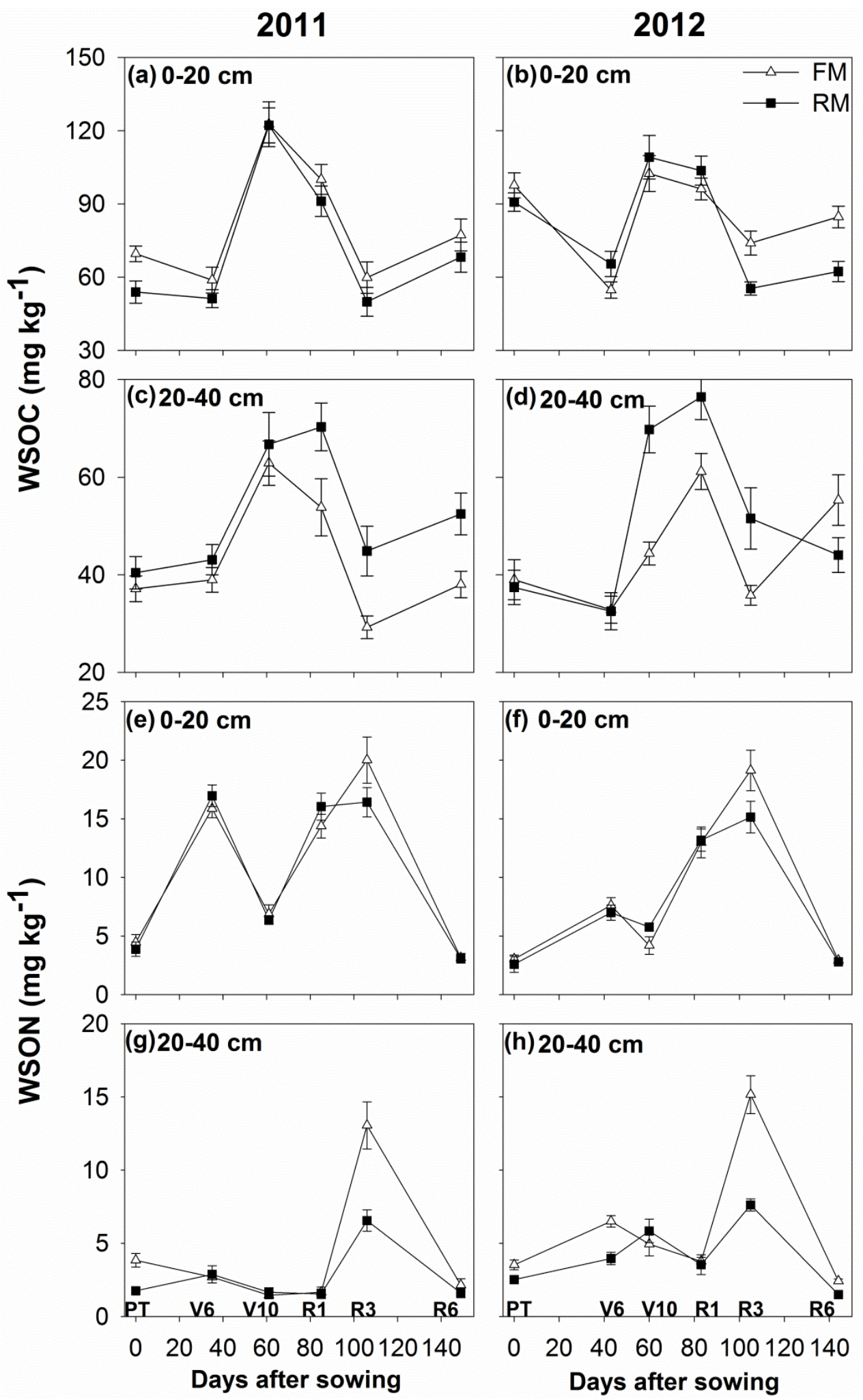

Figure 4. Water soluble organic $C$ and $N$ under different mulching practices in the 0-20 and 20$40 \mathrm{~cm}$ layers during the maize growing season in 2011 and 2012. Error bars represent standard errors of the means $(n=3)$. FM denote the treatment with plastic film mulching during all growing stages, RM denote the treatment with plastic film removal at the silking stage. PT, V6, $V 10, R 1, R 3, R 6$ denote the planting time before fertilization and sowing, the 6th leaf stage, the 10th leaf stage, silking stage, milk stage and physiological maturity, respectively 


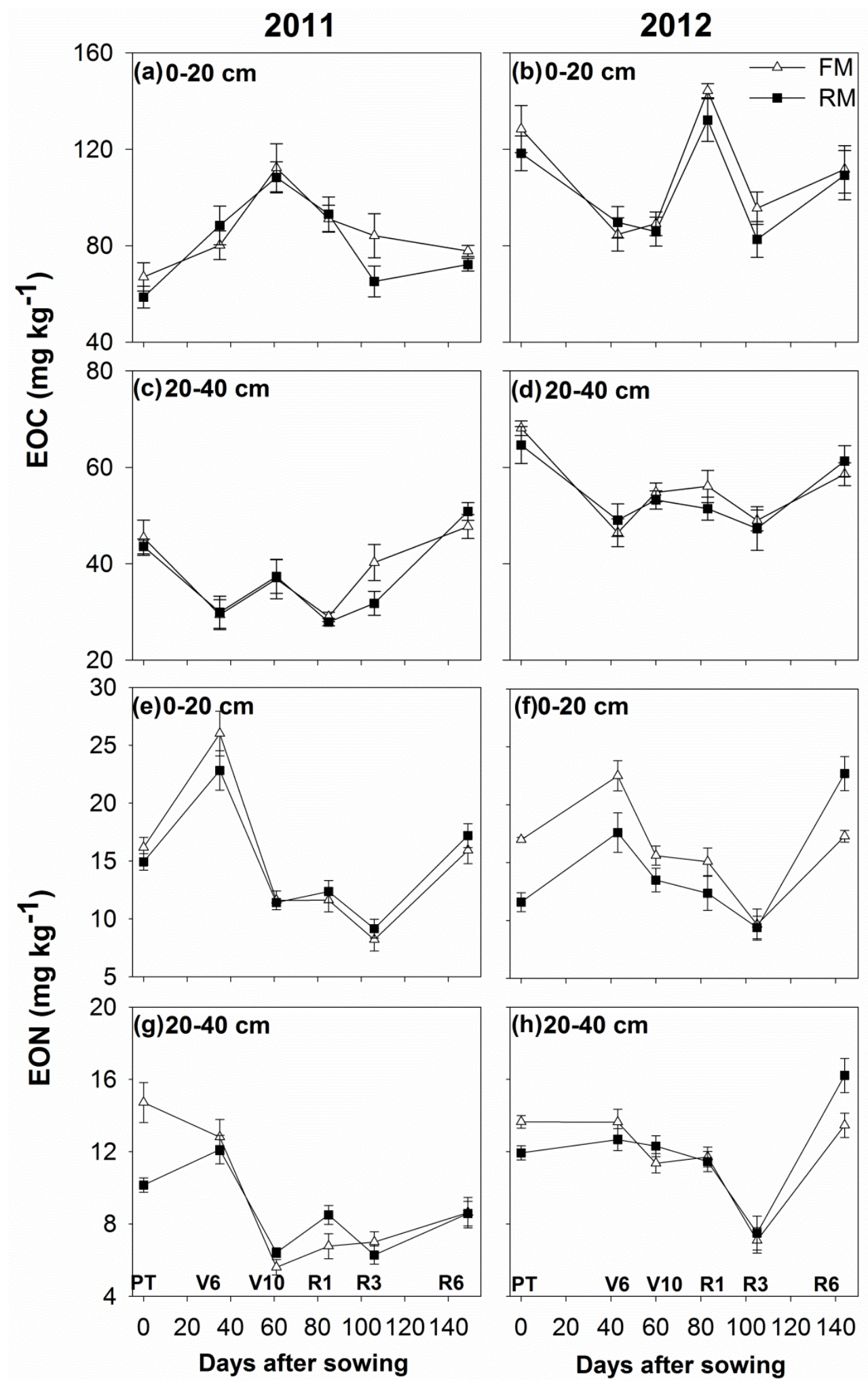

Figure 5. Extractable organic $C$ and $N$ under different mulching practices in the 0-20 and 20 $40 \mathrm{~cm}$ layers during the maize growing season in 2011 and 2012. Error bars represent standard errors of the means $(n=3)$. FM denote the treatment with plastic film mulching during all growing stages, RM denote the treatment with plastic film removal at the silking stage. PT, V6, $V 10, R 1, R 3, R 6$ denote the planting time before fertilization and sowing, the 6th leaf stage, the 10th leaf stage, silking stage, milk stage and physiological maturity, respectively 


\section{Discussion}

\section{Effects of plastic film removal on soil microbial biomass $C$ and $N$}

Maintenance of satisfactory level of SOC and TN are necessary for crop productivity and sustainable agro-ecosystems (Dong et al., 2018), because they play crucial roles in the soil quality and fertility (Zhao et al., 2015). Soil nitrogen $(N)$ is one of the necessary nutrients for plant growth and development, as well as a major nutrient limiting factor for crop yield (Karra et al., 2018; Huang et al., 2018). Soil organic N content of approximately $70 \%-90 \%$ in surface soil could not only maintain soil $\mathrm{N}$ fertility (Xu et al., 2003), but also has an important function for soil $\mathrm{N}$ supply capacity (Ju et al., 2004). However, it is difficult to detect the significant changes of SOC and TN in response to management practices in the short-term (Haynes, 2005; Gong et al., 2009). It is known that soil $\mathrm{C}$ and $\mathrm{N}$ cycling in agro-ecosystems is mediated by soil microorganisms. Due to the rapid generation time of soil microbial biomass, $\mathrm{MBC}$ and $\mathrm{MBN}$ are thought to be the most labile SOM fractions (Brookes, 2001; Chen et al., 2009). MBC regulates soil organic matter decomposition, and $\mathrm{MBN}$ represents both a source and sink of mineral $\mathrm{N}$; thus, they play key roles in maintaining agricultural ecosystems sustainability. Our previous studies have shown that the RM treatment could decrease soil water and temperature during the maize RS compared with the FM treatment (Bu et al., 2013a; Liu et al., 2014a). The lower topsoil moisture and temperature might decrease the decay of plant roots (Liu et al., 2014a), which could lead to increased input of root biomass and rhizodeposits under the RM treatment. In this study, plastic film removal had a significant negtive effect on the MBC contentat R1 of the current growing season in the 0-20 cm layer, but it may promote the MBC content at PT or V6 of the next growing season in the two layers (Fig. 3). Meanwhile, the higher topsoil moisture and temperature provide more substrates for promoting microbial biomass activity, which could lead to higher microbial biomass (Li et al., 2004; Zhou et al., 2012). Taken together, these observations suggest that plastic film removal significantly increased soil microbial biomass at PT or V6 (the maize VS), which was affected by the cumulative effect of early season residue inputs; however, it significantly decreased soil microbial biomass at R3 (the maize RS), which was affected by the lower topsoil moisture and temperature during the current growing season. Moreover, the uptake capacities of inorganic and organic $\mathrm{N}$ by plants varied with development stages and seasonal changes (Simon et al., 2011). In this study, plastic film removal generally increased the MBN content in the dry year (2012), especially in the upper layer of the maize RS (Fig. 3). Considering soil microbes generally compete effectively against plant roots for mineral $\mathrm{N}$ in soils (Dunnet al., 2006), plant roots may shift towards enhancing the utilization of organic $\mathrm{N}$ to avoid the intense competition between plants and microbes during the active growing stages (e.g., the maize $\mathrm{RS}$ with high $\mathrm{N}$ demands), when plant $\mathrm{N}$ demands are highest in the fields with low $\mathrm{N}$ availability (Rennenberg et al., 2009). These results probably reflect that the plastic film removal decreases the decay of plant roots, therefore increases the plant $\mathrm{N}$ demands; therefore, the increasing plant $\mathrm{N}$ demand enhances the utilization of organic $\mathrm{N}$ by plants and increases the microbial $\mathrm{N}$ immobilization.

\section{Effects of plastic film removal on soil dissolved organic $C$ and $N$}

Dissolved organic matter (DOM) is the main source of available $\mathrm{C}$ and nutrients (e.g., $\mathrm{N}$ and $\mathrm{P}$ ) for soil microorganisms and plants, therefore, largely governs nutrient 
cycling in soil ecosystems (Marschner and Kalbitz, 2003). Although DOM fractions (e.g., dissolved Organic C (DOC) and dissolved Organic N (DON)) constitute only a very small proportion of the total SOM pool, they respond rapidly to the changes in soil moisture and temperature resulting from management practices (Luo et al., 2015a, b; 2016). Among the DOM fractions, DOC is retained in mineral soil horizons mostly by sorption onto mineral surfaces (Kaiser and Guggenberger, 2000), and is a readily available substrate for microorganisms and contains a mineralizable proportion of up to 95\% (Don and Kalbitz, 2005); meanwhile, DON is composed of amino acids and other light organic molecules, and may represent a labile $\mathrm{N}$ source for soil microorganisms (Jones and Kielland, 2002). Dissolved organic C and N pools have been measured in various extracts, e.g., hot water (hot water extractable), cold water (simply water soluble, refer to WSOC and WSON used in this study), $0.5 \mathrm{M} \mathrm{K}_{2} \mathrm{SO}_{4}$ (refer to EOC and EON used in this study), and $2 \mathrm{M} \mathrm{KCl}$ etc (Ghani et al., 2003; Jones and Willett, 2006).

WSOC is composed of an array of molecules generally reflecting the composition of total SOC because the soluble phase tends to be in equilibrium with the solid phase of SOC (Chantigny, 2003), and is regarded as an indicator of soil quality and functioning (Saviozzi et al., 2001). In this study, compared with the FM treatment, the RM treatment significantly decreased the WSOC content in the $0-20 \mathrm{~cm}$ layer, whereas significantly increased that in the $20-40 \mathrm{~cm}$ layer at R3 in two years (Fig. 4). This most likely reflects that the plastic film removal helps the upper WSOC infiltrate into the lower layer with soil water migration during the rainy season. EOC is the primary energy source for soil microorganisms and is an indicator of the carbon availability to soil microorganisms; moreover, microbial metabolites also constitute a significant proportion of EOC (Kalbitz et al., 2000). In this study, compared with the FM treatment, the RM treatment significantly decreased the EOC content in the $0-20 \mathrm{~cm}$ layer at R3 in two years; however, in the $20-40 \mathrm{~cm}$ layer, this negative effect was significant in the wet year (2011) and insignificant in the dry year (2012) (Fig. 5). These results probably reflect that plastic film removal leads to a lower microbial reproduction rate and is more significant in the case of wet year and upper layer (high soil water content condition). DON is derived from microbial degradation of fresh and partially decomposed organic residues, including autochthonous soil organic N (Murphy et al., 2000). In general, the salt solution (e.g., $0.5 \mathrm{M} \mathrm{K}_{2} \mathrm{SO}_{4}$ ) extracted more soil organic $\mathrm{N}$ than coldwater. A salt extraction may disturb the adsorption equilibrium on soil surfaces, and organic $\mathrm{N}$ measured in these extracts may include $\mathrm{N}$ originally adsorbed on the surface of soil mineral and organic clays (Murphy et al., 2000). WSON is widely used as a surrogate for DON in soil solutions and includes the DON present in macropores and some smaller pores (Chantigny et al., 2008). In this study, compared with the FM treatment, the RM treatment significantly decreased the WSON content at R3, which may persist into the early stage of the next growing season in the $20-40 \mathrm{~cm}$ layer (Fig. 4). Taken together, these observations suggest that plastic film removal leads to the less release of soluble $\mathrm{N}$ that occurs after microbial degradation of the crop residues and/or the more utilization of soluble $\mathrm{N}$ by plants. Meanwhile, compared with the FM treatment, the RM treatment generally decreased the EON content during the maize VS period, but significantly increased the EON content at R6 in 2012 (Fig. 5). Taken together, these observations suggest that plastic film removal reduces the release of EON, which may be due to the less amounts of extracted $\mathrm{N}$ that are originally adsorbed on the surface of soil mineral and organic clays and/or the greater amounts of extracted $\mathrm{N}$ that are reused by soil microbes. 


\section{Conclusions}

Removing plastic film during the maize RS may promote the aboveground biomass during the VS (V6 or V10) of the next growing season. Meanwhile, compared with the FM treatment, the RM treatment significantly decreased soil microbial biomass and SOM mineralization, whereas significantly increased soil microbial $\mathrm{N}$ immobilization at R3 of the current growing season; however, it significantly increased soil microbial biomass, whereas significantly decreased the DON pools at PT or V6 of the next growing season. Thus, plastic film mulching with film removal during the maize RS could be an excellent option for enhancing crop productivity, improving soil $\mathrm{N}$ availability and maintaining soil quality in the temperature- and rainfall-limited region of northwest China. The response of net soil organic nitrogen mineralization to RM should be further investigated in the future.

Acknowledgements. This research was financially supported by the National Key Research and Development Plan (2017YFD0201807, 2017YFD0200100), National Natural Science Foundation of China (41701332), and Jilin Provincial Science and Technology Development Project of China (20180520048JH).

\section{REFERENCES}

[1] Brookes, P. C. (2001): The soil microbial biomass: concept, measurement and applications in soil ecosystem research. - Microbes and Environments 16: 131-140.

[2] Brookes, P. C., Landman, A., Pruden, G., Jenkinson, D. S. (1985): Chloroform fumigation and the release of soil-nitrogen - a rapid direct extraction method to measure microbial biomass nitrogen in soil. - Soil Biology \& Biochemistry 17: 837-842.

[3] Bu, L. D., Zhu, L., Liu, J. L., Luo, S. S., Chen, X. P., Li, S. Q. (2013a): Source-sink capacity responsible for higher maize yield with removal of plastic film. - Agronomy Journal 105(3): 591-598.

[4] Bu, L. D., Liu, J. L., Zhu, L., Luo, S. S., Chen, X. P., Li, S. Q., Hill, R. L., Zhao, Y. (2013b): The effects of mulching on maize growth, yield and water use in a semi-arid region. - Agricultural Water Management 123: 71-78.

[5] Cabrera, M. L., Beare, M. H. (1993): Alkaline persulfate oxidation for determining total nitrogen in microbial biomass extracts. - Soil Science Society of America Journal 57: 1007-1012.

[6] Chantigny, M. H. (2003): Dissolved and water-extractable organic matter in soils: a review on the influence of land use and management practices. - Geoderma 113: 357380.

[7] Chantigny, M. H., Angers, D. A., Kaiser, K., Kalbitz, K. (2008): Extraction and Characterization of Dissolved Organic Matter. - In: Carter, M. R., Gregorich, E. G. (eds.) Soil Sampling and Methods of Analysis. 2nd Ed. Canadian Society of Soil Science. CRC Press, Boca Raton, FL, pp 617-635.

[8] Chen, H., Hou, R., Gong, Y., Li, H., Fan, M., Kuzyakov, Y. (2009): Effects of 11 years of conservation tillage on soil organic matter fractions in wheat monoculture in Loess Plateau of China. - Soil \& Tillage Research 106: 85-94.

[9] Don, A., Kalbitz, K. (2005): Amounts and degradability of dissolved organic carbon from foliar litter at different decomposition stages. - Soil Biology \& Biochemistry 37: 21712179.

[10] Dong, Q., Yang, Y., Yu, K., Feng, H. (2018): Effects of straw mulching and plastic film mulching on improving soil organic carbon and nitrogen fractions, crop yield and water 
use efficiency in the Loess Plateau, China. - Agricultural Water Management 201: 133143.

[11] Dunn, R. M., Mikola, J., Bol, R., Bardgett, R. D. (2006): Influence of microbial activity on plant-microbial competition for organic and inorganic nitrogen. - Plant and Soil 289: 321-334.

[12] Ghani, A., Dexter, M., Perrott, K. W. (2003): Hot-water extractable carbon in soils: a sensitive measurement for determining impacts of fertilisation, grazing and cultivation. Soil Biology \& Biochemistry 35: 1231-1243.

[13] Gong, W., Yan, X. Y., Wang, J. Y., Hu, T. X., Gong, Y. B. (2009): Long-term manuring and fertilization effects on soil organic carbon pools under a wheat-maize cropping system in North China Plain. - Plant and Soil 314: 67-76.

[14] Haynes, R. J. (2005): Labile organic matter fractions as central components of the quality of agricultural soils: an overview. - Advances in Agronomy 85: 221-268.

[15] Huang, D. D., Chen, X. W., Cao, G. J., Liang, A. Z., Jia, S. X., Liu, S. X. (2018): Effects of long-term conservation tillage on soil nitrogen content and organic nitrogen components in a Chinese mollisol. - Applied Ecology and Environmental Research 16(5): 5517-5528.

[16] Jones, D. L., Kielland, K. (2002): Soil amino acid turnover dominates the nitrogen flux in permafrost-dominated taiga forest soils. - Soil Biology \& Biochemistry 34: 209-219.

[17] Jones, D. L., Willett, V. B. (2006): Experimental evaluation of methods to quantify dissolved organic nitrogen (DON) and dissolved organic carbon (DOC) in soil. - Soil Biology \& Biochemistry 38: 991-999.

[18] Ju, X. T., Liu, X. J., Zhang, F. S. (2004): Effects of long-term fertilization on soil organic nitrogen fractions. - Scientia Agricultura Sinica 37(1): 87-91.

[19] Kaiser, K., Guggenberger, G. (2000): The role of DOM sorption to mineral surfaces in the preservation of organic matter in soils. - Organic Geochemistry 31: 711-725.

[20] Kalbitz, K., Solinger, S., Park, J. H., Michalzik, B., Matzner, E. (2000): Controls on the dynamics of dissolved organic matter in soils: a review. - Soil Science 165: 277-304.

[21] Karra, R., Maslouhi, A., Bamba, Y. O. (2018): Modeling of nitrogen transport in variably saturated soils. - Applied Ecology and Environmental Research 2(6): 1427-1444.

[22] Li, F. M., Song, Q. H., Jjemba, P. K., Shi, Y. C. (2004): Dynamics of soil microbial biomass $\mathrm{C}$ and soil fertility in cropland mulched with plastic film in a semiarid agroecosystem. - Soil Biology \& Biochemistry 36: 1893-1902.

[23] Liang, B., Yang, X. Y., He, X. H., Zhou, J. B. (2011): Effects of 17-year fertilization on soil microbial biomass $\mathrm{C}$ and $\mathrm{N}$ and soluble organic $\mathrm{C}$ and $\mathrm{N}$ in loessial soil during maize growth. - Biology and Fertility of Soils 47: 121-128.

[24] Liang, B. C., Mackenzie, A. F., Schnitzer, M. (1998): Management-induced change in labile soil organic matter under continuous corn in eastern Canadian soils. - Biology and Fertility of Soils 26: 88-94.

[25] Liu, C. A., Jin, S. L., Zhou, L. M., Jia, Y., Li, F. M., Xiong, Y. C., Li, X. G. (2009): Effects of plastic film mulch and tillage on maize productivity and soil parameters. European Journal of Agronomy 31: 241-249.

[26] Liu, J. L., Bu, L. D., Zhu, L., Luo, S. S., Chen, X. P., Li, S. Q. (2014a): Optimizing plant density and plastic film mulch to increase maize productivity and water-use efficiency in semiarid areas. - Agronomy Journal 106: 1138-1146.

[27] Liu, J. L., Zhu, L., Luo, S. S., Bu, L. D., Chen, X. P., Yue, S. C., Li, S. Q. (2014b): Response of nitrous oxide emission to soil mulching and nitrogen fertilization in semiarid farmland. - Agriculture Ecosystems \& Environment 188: 20-28.

[28] Liu, J. L., Zhan, A., Chen, H., Luo, S. S., Bu, L. D., Chen, X. P., Li, S. Q. (2015): Response of nitrogen use efficiency and soil nitrate dynamics to soil mulching in dryland maize (Zea mays L.) fields. - Nutrient Cyclingin Agroecosystems 101: 271-283. 
[29] Liu, J. L., Chen, X. P., Zhan, A., Luo, S. S., Chen, H., Jiang, H. B., Huang, X. Y., Li, S. Q. (2016): Methane uptake in semiarid farmland subjected to different mulching and nitrogen fertilization regimes. - Biology and Fertility of Soils 52: 941-950.

[30] Liu, X. E., Li, X. G., Hai, L., Wang, Y. P., Fu, T. T., Turner, N. C., Li, F. M. (2014c): Film-Mulched Ridge-Furrow Management Increases Maize Productivity and Sustains Soil Organic Carbon in a Dryland Cropping System. - Soil Science Society of America Journal 49: 1182-1185.

[31] Liu, Y., Yang, S. J., Li, S. Q., Chen, X. P., Chen, F. (2010): Growth and development of maize (Zea mays L.) in response to different field water management practices: Resource capture and use efficiency. - Agricultural and Forest Meteorology 150: 606-613.

[32] Luo, S. S., Zhu, L., Liu, J. L., Bu, L. D., Yue, S. C., Shen, Y. F., Li, S. Q. (2015a): Sensitivity of soil organic carbon stocks and fractions to soil surface mulching in semiarid farmland. - European Journal of Soil Biology 67: 35-42.

[33] Luo, S. S., Zhu, L., Liu, J. L., Bu, L. D., Yue, S. C., Shen, Y. F., Li, S. Q. (2015b): Mulching effects on labile soil organic nitrogen pools under a spring maize cropping system in semiarid farmland. - Agronomy Journal 107: 1465-1472.

[34] Luo, S. S., Zhu, L., Liu, J. L., Bu, L. D., Yue, S. C., Shen, Y. F., Li, S. Q. (2016): Response of labile organic $\mathrm{C}$ and $\mathrm{N}$ pools to plastic film removal from semiarid farmland soil. - Soil Use and Management 32(4): 535-542.

[35] Luo, S. S., Wang, S. J., Yao, P. Y., Guo, D., Li, X. J., Li, S. Q., Tian, C. J. (2019): Soil microbial communities under film mulching and $\mathrm{N}$ fertilization in semiarid farmland. Nutrient Cycling in Agroecosystems 114: 157-170.

[36] Marschner, B., Kalbitz, K. (2003): Controls of bioavailability and biodegradability of dissolved organic matter in soils. - Geoderma 113: 211-235.

[37] Murphy, D. V., Macdonald, A. J., Stockdale, E. A., Goulding, K. W. T., Fortune, S., Gaunt, J. L., Poulton, P. R., Wakefield, J. A., Webster, C. P., Wilmer, W. S. (2000): Soluble organic nitrogen in agricultural soil. - Biology and Fertility of Soils 30: 374-387.

[38] Norman, R. J., Edberg, J. C., Stucki, J. W. (1985): Determination of nitrate in soil extracts by dual-wavelength ultraviolet spectrophotometry. - Soil Science Society of America Journal 49: 1182-1185.

[39] Rennenberg, H., Dannenmann, M., Gessler, A., Kreuzwieser, J., Simon, J., Papen, H. (2009): Nitrogen balance in forest soils: nutritional limitation of plants under climate change stresses. - Plant Biology 11: 4-23.

[40] Ritchie, S. W., Hanway, J. J., Benson, G. O. (1992): How a Corn Plant Develops. Special Report No. 48. Iowa State University, Cooperative Extension Service, Ames, IA, http://maize.agron.iastate.edu/corngrows.html.

[41] Ryan, J., Masri, S., Singh, M. (2009): Seasonal changes in soil organic matter and biomass and labile forms of carbon as influenced by crop rotations. - Communications in Soil Science and Plant Analysis 40: 188-199.

[42] Saviozzi, A., Levi-Minzi, R., Cardelli, R., Riffaldi, R. (2001): A comparison of soil quality in adjacent cultivated, forest and native grassland soils. - Plant and Soil 233: 251259.

[43] Simon, J., Dannenmann, M., Gasche, R., Holst, J., Mayer, H., Papen, H., Rennenberg, H. (2011): Competition for nitrogen between adult European beech and its offspring is reduced by avoidance strategy. - Forest Ecology and Management 262: 105-114.

[44] Vance, E. D., Brookes, P. C., Jenkinson, D. S. (1987): An extraction method for measuring soil microbial biomass-C. - Soil Biology \& Biochemistry 19: 703-707.

[45] Wang, F. X., Feng, S. Y., Hou, X. Y., Kang, S. Z., Han, J. J. (2009): Potato growth with and without plastic mulch in two typical regions of Northern China. - Field Crops Research 110: 123-129.

[46] Wang, L., Li, X. G., Lv, J., Fu, T., Ma, Q., Song, W., Wang, Y. P., Li, F. M. (2017): Continuous plastic-film mulching increases soil aggregation but decreases soil $\mathrm{pH}$ in semiarid areas of China. - Soil \& Tillage Research 167: 46-53. 
[47] Xu, Y. C., Shen, Q. R., Ran, W. (2003): Content and distribution of forms of organic N in soil and particle size fractions after long-term fertilization. - Chemosphere 50(6): 739745.

[48] Zhao, X., Wu, P., Gao, X., Persaud, N. (2015): Soil quality indicators in relation to land use and topography in a small catchment on the Loess Plateau of China. - Land Degradation \& Development 26(1): 54-61.

[49] Zhou, L. M., Jin, S. L., Liu, C. A., Xiong, Y. C., Si, J. T., Li, X. G., Gan, Y. T., Li, F. M. (2012): Ridge-furrow and plastic-mulching tillage enhances maize-soil interactions: Opportunities and challenges in a semiarid agroecosystem. - Field Crops Research 126: 181-188. 